\title{
Mapping Soil Erosion Prevention Using an Ecosystem Service Modeling Framework for Integrated Land Management and Policy
}

\author{
Carlos A. Guerra, Teresa Pinto-Correia \& Marc J. Metzger
}

\begin{abstract}
Current spatially explicit approaches to map and assess ecosystem services are often grounded on unreliable proxy data based on land use/cover to derive ecosystem service indicators. These approaches fail to make a distinction between the actual service provision and the underlying eco-system capacity to provide the service. We present an integrative conceptual framework to estimate the provision of soil erosion prevention by combining the structural impact of soil erosion and the social-ecological processes that allow for its mitigation. The framework was tested and illustrated in the Portel municipality in Southern Portugal, a Mediterranean silvo-pastoral system that is prone to desertification and soil degradation. The results show a clear difference in the spatial and temporal distribution of the capacity for ecosystem service provision and the actual ecosystem service provision. It also shows that although the average actual ecosystem service provision in the region is sufficient to mitigate the existing structural impact, vulnerable areas can be identified where significant soil losses are not mitigated at present. This becomes more significant when comparing different land management intensities. Considering these results, we argue that the general assumption that there is an almost direct relation between the capacity for ecosystem service provision of a given area and the actual ecosystem service provision is wrong. We also discuss how the framework presented here could be used to support land management and policy, and how it can be adapted for other regulating services
\end{abstract}

Key words:

Regulating services; spatial modeling; remote sensing; USLE; montado; farm system; land use; landscape

Ecosystems

ISSN 1432-9840

Ecosystems

DOI 10.1007/s10021-014-9766-4 